\title{
Kahenman and Tversky's Research on Heuristics and Its Application to Junior Athletic Development and the College Recruiting Process
}

\author{
Brendan M. Ryan ${ }^{1}$ \\ ${ }^{1}$ Wesley Chapel, Florida, USA \\ Correspondence: Brendan M. Ryan, Wesley Chapel, Florida, USA. E-mail: brendan@bmrgolfmanagement.com
}

Received: February 6, 2017

Accepted: February 20, 2017

Online Published: April 5, 2017

doi:10.5539/hes.v7n2p23

URL: http://doi.org/10.5539/hes.v7n2p23

\begin{abstract}
This paper will apply the work of Amos Tversky and Daniel Kahneman in Prospect theory to the college recruiting process. Prospect theory challenges one of the fundamental ideas of Economics; humans are rational creatures and make rational decisions. The theory demonstrates that in fact, often humans do not make rational decisions and are instead subject to "heuristics". Heuristics are mental shortcuts individual use to solve problems. The paper will both explain heuristics, as well as demonstrate how coaches, administrators, and junior athletes should be aware of the role of heuristics in both long-termdevelopments, as well as the college recruitment process.
\end{abstract}

Keywords: prospect theory, college athletics, NCAA athletics, Daniel Kahneman, heuristics

\section{Introduction}

In the early 1970s, psychologists Amos Tversky and Daniel Kahneman worked at the Hebrew University of Jerusalem doing research in cognitive science for basic human error. This research, which would eventually lead to the development of Prospect Theory, led them to expand on Chester Barnard and Herbert A. Simon's work on heuristics (Barnard \& Simon, 1947; Tversky \& Kahneman, 1973). Barnard and Simon's research demonstrates people often rely on heuristics; an approach to problem-solving, learning, or discovery that employs a mode of decision making that is only sufficient, but not perfect, in its pursuit of solving problems. Kahenman and Tversky's work added to Barnard and Simon's work (Tversky \& Kahneman, 1973). Eventually Kahneman and Tverksy collected evidence that humans suffer from three common heuristics - anchoring, availability, and representativeness.

This article examines how heuristics impact high school athletes, coaches, college administrators and families in both their long-term development, as well as the pursuit of playing a college sport. The author hopes that by educating coaches, college administrators, college bound student athletes and their parents about the roles heuristics play in the long-term development and the recruiting process, athletes will be better informed.

The college search process increasingly competitive; there are more foreign and domestic students in pursuit of college athletics and they are engaged in more sophisticated training, with many choosing early specialization. In sports like gymnastics, with short life spans of athletes, there may be no choice but to be engaged early however, many sports like soccer, hockey, golf and tennis have much longer life spans, in some cases well over 10 years. When youth what to specialize, they need access about the risks of early specialization, which has been linked to increased injury and burnout; playing daily over several years becomes grueling even for the most passionate player.

Young athletes, parents and coaches should be aware of the work of Dr. Richard Learner, a professor at Tufts University. Dr. Learner's work focuses on Positive Youth Development (PYD), explores adolesences, trying to better understand their struggles and create tools to help them succeed. PYD asserts that all adolescents have both strengths and weaknesses that need proper nurturing (Lerner, 2006). Proper nurturing involves coaches which leverage available resources. When students are in environments where that feel nurtured, they are more likely to have long term success (Lerner, Phelps, Forman, \& Bowers, 2009).

Diversity in schedule allows athletes to gain experience in skills that are transferable to sport and beyond. For example, a soccer player may learn about patience and shifting focus from a reading club. Likewise, a golfer 
might learn about concentration from playing chess or doing yoga. Having diverse skill sets, especially at the elite or near elite level will never hurt an athlete.

\section{The Three Heuristics: Anchoring, Availability, and Receptiveness}

The three types of heuristics are anchoring, availability, and representativeness. Anchoring is a cognitive bias where individual create a shortcut based on comparing data to an example or anchor. For example, if you ask someone from the United States, how many people live in Canada, they are likely to way over estimate. Why? Because the United States has about 320 million people and as an anchor, it seems like Canada, with a similar land mass, should have significantly more than 32 million people.

Availability heuristics can be applied when evaluating everything from a specific concept to a method or decision, and they influence people to believe that the information most easily recalled is also very likely to be the most reliable. In a specific set of experiments on availability, Tversky and Kahneman asked participants, "If a random word is taken from an English text, is it more likely that the word starts with a K, or that $\mathrm{K}$ is the third letter?" (Tversky \& Kahneman, 1973). Their hypothesis, which proved correct, was that people would pick a word starting with " $K$ " because they would have a much easier time recalling words that start with " $K$ " than the third letter starting with " $K$ ".

Per Baumeister and Bushman (2010), the representativeness heuristic is the tendency to examine events against the most typical case. The most famous example of representativeness is what Tversky and Kahenman call the "Linda Problem" (Tversky \& Kahenman, 1983). In this example, participants receive a survey with the description of a person named "Linda". The description is as follows:

Linda is 31 years old, single, outspoken, and very bright. She majored in philosophy. As a student, she was deeply concerned with issues of discrimination and social justice and also participated in anti-nuclear demonstrations.

The researchers asked, which is more probable?

1) Linda is a bank teller.

2) Linda is a bank teller and is active in the feminist movement.

Of course, this is a conjunction fallacy, meaning the probability of these two events occurring together must be less than or equal to the probability of them occurring alone. People choose the second option more often because the "active in the feminist movement" seems more "representative" or likely of the description of Linda.

\section{How These Heuristics Impact Long-Term Development and the College Recruiting Process}

Coaches in college athletics routinely use anchoring to demonstrate proficiency in recruiting to their direct supervisor. In many cases, this supervisor is an administrator, who often lacks specific training in the sport inlong-term development. If the team is struggling and the administrator questions the coach about the performance of the players, the coach can rebut by saying that during the last signing period, the team recruited the hundredth-ranked junior athlete in their sport and top 5 in the state. As an anchor to the administrator, this sounds like the coach is doing a very solid job and no more discussion is necessary.

Using rankings as an anchor however may not be ideal for student athlete's development; it takes the emphasis off building skill and onto performance. Examples of skills, in a sport like soccer would be passing, positioning, and footwork. Taking the emphasis away from building strong skills impacts the long-term trajectory of the player; less skills equals less ability to maximize potential. The emphasis on results, also creates what sports psychologist call an ego orientation. Playing for scholarship or results impacts motivation. Finally, results favor early biological developers for scholarships.

The availability heuristic in college recruiting is demonstrated in families understanding of the number of spots available for college sports and professional sports. In golf, there are only about 300 Men's Division One Schools and 62 Power Conference teams that support college golf. Most of these schools will take an average of two players per year. Among all junior golfers in the world, there are only 600 Division One and 124 Power conference spots. Considering that the European Golf Association suggests that there are 47,178 junior players in Germany, 47,333 junior players in Sweden and 8,478 junior players in Denmark. Add at least 50,000 junior players in America. Those 600 spots are significantly more competitive than people think.

The probability of playing professionally is less. According to the NCAA website, there are 34,198 baseball players, 738 are drafted, 18,697 men's basketball players of which 46 are drafted, 72,788 men's football players of which 256 will be drafted and 4,071 men's hockey players of which 60 will be drafted. That means the odds 
in baseball are $2 \%, 1 / 5$ of a percent, $.003 \%$ in football and $1.4 \%$ in hockey. These numbers are tobe drafted, not actually participants in professional sport. That number would be even less.

Representativeness is demonstrated in the college recruiting process when parents or coaches use non-quantitative data in comparing their athlete to others who have committed to prestigious academic or athletic schools. For example, parents might say that their student is much more "talented" than the young man who always beats their student or that their student is "better" academically. As such the example lack substance and instead of empowering the student-athlete, the comments are more likely to encourage cognitive dissidence (Lake Wobegon Effect) and narcissism than support the healthy development of a student-athlete.

Although coaching is important, they are unlikely to be the determining factor in the success of an athlete. When parents or coaches become an anchor in development, this can be a problem for the development of the athlete. Coaches instead, should be strong role models and educators teaching students skills and the planning necessary to reach their goals. Instead of pushing kids towards ego orientation goals of scores (outcomes) and scholarships, parents should push their kids to use sport as a healthy outlet to exercise and build skills like teamwork and learning to set goals and hard work.

\section{Advice for Coaches When Dealing with Parents}

When parents and students become ego oriented, focusing on scholarship or brand of school, instead of fit, coaches should take approperiate steps to educate about Long Term Development. In this section, I will share some of the different techniques I have used over my coaching career.

Coaches are responsible for creating not only athletic excellence but also social responsibility through demonstrating a proper value system to their student athletes. Coaches are encouraged to use different resources to parents in order to help education them about the process. This could include work by Mischel's work on instant gratification, Dweck's work on mindset, Ericcson's work on deliberate practice as well as countless others.

It is extraordinarily important to education parents; we are not our children. When parents dictate plans for colleges including rankings and location are questions about the athletic or academic standard, neither parent nor child has any idea. Not withstanding the fact, the rankings start at 0 and so schools are not necessarily guaranteed anything, this is a major issue. What happens if the student enrolls in the 26th school and its a perfect fit for them, are they a failure? According to the definition created; yes.

Maybe the best advice comes via Mr. Steve Runge. Steve was a standout golfer at Ohio State who went on to play and win professional three times. A soft-spoken man, with tons of experience in elite athletics says "if you are good enough, you will make it". Although this might be a slight oversimplification, it is very sound advice for parents. The cream always rises to the top.

\section{Conclusion}

Kahenman and Tversky's (1973) work on Prospect Theory challenged the idea that people made rational decisions, by demonstrating that people are subject to heuristics. These heuristics are availability, anchoring, and representativeness. This paper has demonstrated how these heuristics, when manifested in the long-term development of athletes can damage performance. Athletes, coaches, and sports administrators are advised to understand their heuristics and the role they play in long-term development. By understanding their existence, steps can be taken to support healthy athletes in their personal development of skill and passion for competition and comradery. 


\section{References}

Aspen Institute: Project Ply. (n.d.). Retrieved January 4, 2017, from http://www.aspenprojectplay.org/

Barnard, C., \& Simon, H. A. (1947). Administrative behavior: A study of decision-making processes in administrative organization. Macmillan, New York.

Baumeister, R. F., \& Bushman, B. J. (2010). Social Psychology and Human Nature: International Edition. Belmont, USA: Wadsworth.

Dweck, C. S. (2016). Mindset: The new psychology of success. New York: Ballantine Books.

Ericsson, K. A. (2016). Peak: Secrets from the New Science of Expertise. Boston: Houghton Mifflin Harcourt.

European Golf Assocation. (n.d.). Retrieved January 2, 2017, from http://www.ega-golf.ch/federations

Kahneman, D. (2011). Thinking, Fast and Slow. Farrar, Straus and Giroux.

Kahneman, D., \& Frederick, S. (2002). Representativeness Revisited: Attribute Substitution in Intuitive Judgment. In G. Thomas, G. Dale, \& K. Daniel (Eds.), Heuristics and Biases: The Psychology of Intuitive Judgment (pp. 51-52). Cambridge: Cambridge University Press. https://doi.org/10.1017/CBO9780511808098.004

Lerner, J. V., Phelps, E., Forman, Y., \& Bowers, E. P. (2009). Positive youth development. In Handbook of Adolescent Psychology. https://doi.org/10.1002/9780470479193.adlpsy001016

Lerner, R. M. (2006). Developmental science, developmental systems, and contemporary theories of human development. In R. M. Lerner (Ed.), Handbook of Child Psychology (6th ed., pp. 1-17). Hoboken, NJ: Wiley.

Mischel, W. (1968). Personality and assessment. New York: Wiley.

Probability of Competing Beyond High School. (2016, July 11). Retrieved January 4, 2017, from http://www.ncaa.org/about/resources/research/probability-competing-beyond-high-school

Tversky, A., \& Kahneman, D. (1973). Availability: A heuristic for judging frequency and probability. Cognitive Psychology, 5(2), 207-232. https://doi.org/10.1016/0010-0285(73)90033-9

Tversky, A., \& Kahneman, D. (1983). Extensional versus intuitive reasoning: The conjunction fallacy in probability judgement. Psychological Review, 90, 293-315. https://doi.org/10.1037/0033-295X.90.4.293

\section{Copyrights}

Copyright for this article is retained by the author(s), with first publication rights granted to the journal.

This is an open-access article distributed under the terms and conditions of the Creative Commons Attribution license (http://creativecommons.org/licenses/by/4.0/). 